\title{
Physical Properties of Elastic Duplicating Materials
}

R. G. CRAIG and F. A. PEYTON

University of Michigan, School of Dentistry, Ann Arbor, Michigan

Agar has been used for a number of years in the preparation of elastic duplicating materials. These duplicating materials have been used mainly in partial denture prosthesis for the preparation of a duplicate refactory cast of the original stone cast of the patient's mouth. Since moderately large quantities of duplicating materials are used in these procedures, the low cost and reversibility of the agar materials are a definite advantage.

The mercaptan and silicone rubber elastic impression materials have not been used extensively in duplicating procedures because of their high cost and the fact that these materials, once set, are irreversible. Recently, a plastic duplicating material has been developed which is a reversible polyvinyl chloride plastic gel. Because of its chemical and physical nature, this material has elastic properties somewhat different from the agar compounds.

The agar duplicating compounds are composed primarily of agar and water but may also contain borax to increase the strength, salts to accelerate the setting of the investment, and other ingredients. Cellulose fibers, waxes, and fillers, which may be found in impression compounds, generally are omitted from duplicating compounds, since the duplicating materials are often stored in the sol state for extended periods and these ingredients tend to separate under this condition of storage. Since the duplicating compounds may be stored at temperatures of $130^{\circ}-150^{\circ} \mathrm{F}$, their resistance to thermal degradation is an important property.

The basic composition of the agar impression compounds is much the same as for the agar duplicating compounds. The principal difference is that the impression compounds may contain 10-15 per cent agar, while the duplicating materials may contain only 5 per cent agar and, as just indicated, need not contain waxes, fillers, and other modifiers common to impression materials. In fact, agar impression materials have been used as duplicating compounds by simply diluting the impression material with an equal amount of water.

The properties of the agar impression compounds have been studied by numerous investigators. Skinner and Kern ${ }^{1}$ determined the linear-dimensional changes in air and subsequently in water of various agar impression compounds. They also measured the compressive properties of proportional limit, maximum flexibility, and crushing strength, as well as the plastic flow properties of these agar materials. Paffenbarger ${ }^{2}$ reported the compressive properties of strength, deformation, set, and stiffness of a number of agar compounds. The temperature of gel formation and the impression-

This report represents the partial results of studies supported by Contract No. DA-49-007-MD-938 between the Office of the Surgeon General, Department of the Army, and the University of Michigan.

Received for publication October 21, 1959. 
taking qualities, as measured by the present A.D.A. master model for agar hydrocolloid materials, were also determined. Luster ${ }^{3}$ reported the effect of environmental factors of air, water, and inorganic sulfate solutions on the dimensional stability of agar gels. Phillips and co-workers ${ }^{4}$ also measured the dimensional changes of agar gels under various conditions.

The properties of elastic duplicating materials have received little attention, with only limited information available in the literature. Margetis and Hansen, ${ }^{5}$ however, recently studied the changes in agar duplicating materials on heating and storage by measuring changes in the $\mathrm{pH}$ and viscosity of the sols and the crushing times of the gels. These values indicated a gradual degradation of the agar material over a 32-day period when stored at $52^{\circ} \mathrm{C}$. $\left(125.6^{\circ} \mathrm{F}\right.$.).

TABLE 1

DUPLICATION AND IMPRESSION MATERIALS STUDIED

\begin{tabular}{|c|c|c|}
\hline Code Letter & Product & Supplier \\
\hline \multirow{3}{*}{$\begin{array}{l}\text { A } \ldots \ldots \\
\text { B..... } \\
\mathrm{C} \ldots \ldots \ldots \\
\mathrm{D} \ldots \ldots \\
\mathrm{E} \ldots \ldots\end{array}$} & \multicolumn{2}{|c|}{ Duplicating Compounds } \\
\hline & $\begin{array}{l}\text { Copymaster Duplicating Material } \\
\text { Lastic } \\
\text { Nobiloid } \\
\text { Surgident Duplicating Compound } \\
\text { Ticonium Special } \\
\text { "Van R" Laboratory Duplicating Material }\end{array}$ & $\begin{array}{l}\text { L. D. Caulk Co. } \\
\text { Durallium Products Corp. } \\
\text { Nobilium Products, Inc. } \\
\text { Surgident, Ltd. } \\
\text { Dental Perfection Co. } \\
\text { "Van R" Dental Products }\end{array}$ \\
\hline & \multicolumn{2}{|c|}{ Impression Compounds } \\
\hline $\begin{array}{l}\mathrm{G} \ldots \\
\mathrm{H} \ldots \\
\mathrm{I} \ldots\end{array}$ & $\begin{array}{l}\text { Deelastic } \\
\text { Dentocoll } \\
\text { Surgident }\end{array}$ & $\begin{array}{l}\text { Kerr Manufacturing Co. } \\
\text { L. D. Caulk Co. } \\
\text { Surgident, Ltd. }\end{array}$ \\
\hline
\end{tabular}

The present investigation represents a portion of a study being conducted on elastic duplicating materials and consists mainly of an initial comparison of the properties of duplicating materials with agar impression compounds. The physical properties of compressive strength, tear strength, stress-strain properties, per cent set, crushing time, impression qualities, and gelation temperature were measured. In addition, the properties of a number of experimental agar gels were determined, in order to examine the effect of the agar source and composition on physical properties.

Other phases of this study, to be reported at a later date, are (1) the accuracy of duplicating materials, (2) the effect of aging on duplicating compounds, and (3) the visco-elastic behavior of these materials.

\section{MATERIALS AND METHODS}

The commercial duplicating materials investigated and the suppliers are listed in Table 1, with a code letter for each material. The materials are referred to by code letter because this study is an evaluation of the general properties of elastic dupli- 
cating materials, and a high or low value for any particular property does not imply that the material is a superior or inferior product. In fact, it is known that each of the materials is used routinely and gives acceptable results. All the duplicating compounds are hydrocolloid materials except material $B$, which is a reversible plastic gel.

Three hydrocolloid elastic impression materials were selected from the large number commercially available on the basis of general differences in physical properties. These products also are listed in Table 1 with a code letter.

Experimental agar gels were prepared from four different commercially available dental-grade agars* used in these investigations. Samples from different batches of these raw agars were obtained and the physical properties determined, in order to observe differences as a result of the source of supply. A dental-grade agar was also used to prepare experimental gels. Five lots of this type of agart taken over an 18 month period were examined.

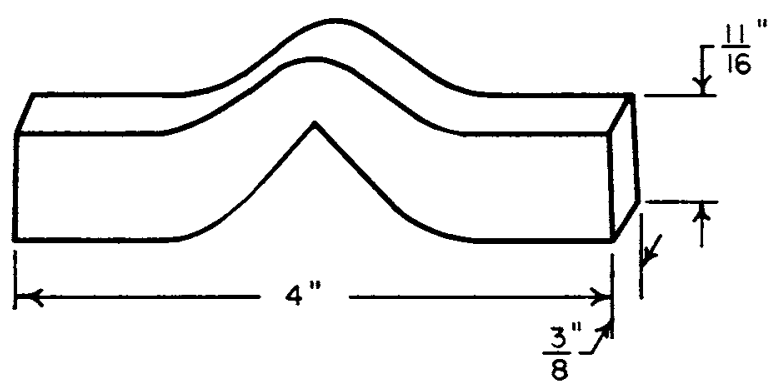

FIG. 1.-Sketch of a tear specimen

Specimens used for the determination of compressive strength, stress-strain curves, per cent set, and crushing time were cylinders $3 / 4$ inch high by $1 / 2$ inch in diameter. These cylindrical specimens of agar impression or duplication compounds were prepared by liquefying them in boiling water and using specimen molds as described in A.D.A. specification No. 11 for hydrocolloid impression material, section 4.4.5.1. ${ }^{6}$ The duplicating compounds were poured when the temperature was between $140^{\circ}$ and $150^{\circ} \mathrm{F}$. The impression compounds were tempered according to the manufacturer's directions. Duplicating material B was poured at the storage temperature of $210^{\circ} \mathrm{F}$. After pouring, the specimens were stored in a humidor at 100 per cent relative humidity for 1 hour until tested.

The tear specimens used had the shape of the ASTM tear-test die C (ASTM Test D624-54). ${ }^{7}$ The tear test has been used to evaluate rubber materials. The shape and dimensions of the specimens are indicated by the sketch in Figure 1. The mold for the tear specimens was prepared from a casting plastic, and the top and bottom of the mold were formed by glass plates. The specimens were prepared and stored as indicated for the compression specimens.

The dry strip agar was cut into small pieces, and the powdered forms were used as received. $10 \mathrm{gm}$. of agar plus $190 \mathrm{gm}$. of water were placed in half-pint mason jars.

* Japanese strip agar, Kobe \#1, Portuguese agar, Type PAR 40, and Spanish agar, Type PAR 80; T. M. Duché and Sons, Inc.

t American Agar and Chemical Company. 
After the agar was thoroughly wetted, the sealed jar was placed in an autoclave for 15 minutes at $265^{\circ} \mathrm{F}$. After this time, the pressure was released and the agar sols allowed to cool to room temperature.

The compressive strength of the various materials was determined on the cylindrical specimens. The load required to rupture the specimen was determined, using an Instron Testing Machine. The rate of deformation during testing was varied from 1 to 20 inches/minute. It was observed that a maximum compressive strength resulted at a deformation rate of approximately 10 inches/minute, for which reason the majority of the testing was carried out at this deformation rate.

The stress-strain curve may also be obtained from the load and deformation data. The stress-strain curves were plotted from the data obtained at a deformation rate of 10 inches/minute. These curves permitted the determination of the stiffness, proportional limit, and per cent compression of the agar materials.

The tear strength of elastic duplicating and impression materials is a most important property because these materials must have sufficient strength that they may be removed from undercut areas and interproximal spaces without tearing. The load required to continue tearing the specimen was determined by using the Instron Tester. The load divided by the thickness of the specimen in inches was a measure of the tear strength and is reported in pounds per inch of notch or, more simply, pounds per inch.

The per cent set after 12 per cent strain was determined on an instrument developed by Cresson. ${ }^{8}$ The instrument had a dial gauge sensitive to 0.001 inch, was mounted on a steady stand, and was equipped with a screw to allow a cylindrical specimen to be compressed the desired 12 per cent. The sample was compressed 12 per cent and the pressure maintained 1 minute, after which the sample was allowed to rest with no pressure for 1 minute, and the specimen height was measured. Knowing the original and final specimen length, the per cent set may be calculated.

A crushing-time test similar to that proposed by Margetis and Hansen ${ }^{5}$ was used. The modified compression-testing apparatus described by Paffenbarger ${ }^{2}$ was convenient for performing the crushing-time test. The cylindrical specimens were loaded with weights varying from 1,100 to $3,600 \mathrm{gm}$, and the time from the load application to the rupture of the specimen was determined in seconds. Variation in the load was necessary, since no single load could be found which would give reasonable crushing times for agar impression, duplication, and experimental materials.

The A.D.A. master model for testing hydrocolloid impression materials ${ }^{6}$ was used to give a general evaluation of the impression qualities of the duplicating materials. This master model has five posts, two of which are cylindrical, and the other three have varying degrees of undercut. A snap removal of the master model was carried out, and improved stone was used to prepare the duplicate model.

The gelation temperatures were measured according to the directions of the A.D.A. specification No. 11 for hydrocolloid impression materials. ${ }^{6}$ The test consists of inserting a metal tube into the impression material at various times as the material cools from a sol to a gel. The gel temperature is that temperature at which a clear impression of the inside and outside of the metal tube is obtained and none of the material clings to the walls of the tube. 


\section{RESULTS}

Stress-strain properties.-The stress-strain curves were determined for all the duplicating and impression compounds listed. The values for the initial slope of the straight-line portion of the curves and the proportional limit as indicated by flattening of the curve prior to fracture are listed in Table 2. In addition, the ultimate per cent compressions also are reported in this table. The ultimate compressive strength also may be obtained from these curves, and this property will be discussed in the following section. Examples of the various types of stress-strain curves obtained are presented in Figure 2 for materials $\mathrm{B}, \mathrm{D}, \mathrm{E}$, and $\mathrm{I}$.

TABLE 2

STRESS-STRAIN PROPERTIES OF DUPLICATING AND IMPRESSION COMPOUNDS

\begin{tabular}{|c|c|c|c|}
\hline Material & $\begin{array}{c}\text { Stiffness } \\
\left(\mathrm{lb} / \mathrm{in}^{2}\right)\end{array}$ & $\begin{array}{l}\text { Prop. Limit } \\
\quad\left(\mathrm{lb} / \mathrm{in}^{2}\right)\end{array}$ & $\begin{array}{l}\text { Ultimate } \\
\text { Compression } \\
\text { (per cent) }\end{array}$ \\
\hline \multirow{3}{*}{$\begin{array}{l}\mathrm{A} \ldots \ldots \\
\mathrm{B} \ldots \ldots \\
\mathrm{C} \ldots \ldots \\
\mathrm{D} \ldots \ldots \\
\mathrm{E} \ldots \ldots \\
\mathrm{F} \ldots \ldots\end{array}$} & \multicolumn{3}{|c|}{ Duplicating Compounds } \\
\hline & $\begin{array}{r}150 \\
100 \\
70 \\
120 \\
70 \\
140\end{array}$ & $\begin{array}{r}59 \\
130 \\
51 \\
54 \\
39 \\
58\end{array}$ & $\begin{array}{l}39 \\
60 \\
46 \\
36 \\
32 \\
31\end{array}$ \\
\hline & \multicolumn{3}{|c|}{ Impression Compounds } \\
\hline $\begin{array}{l}\mathbf{G} \ldots \ldots \ldots \ldots \\
\mathbf{H} \ldots \ldots \ldots \ldots\end{array}$ & $\begin{array}{l}210 \\
200 \\
200\end{array}$ & $\begin{array}{r}72 \\
102 \\
95\end{array}$ & $\begin{array}{l}37 \\
46 \\
42\end{array}$ \\
\hline
\end{tabular}

The deformation rate was 10 inches/minute, with the result that the complete stress-strain curve for any of the samples was obtained in less than 3 seconds. On the basis of unpublished flow studies, the curves represented primarily the elastic behavior of the materials, and any viscous effect was neglected. Material I was an agar impression compound and, like the other impression compounds $\mathrm{G}$ and $\mathrm{H}$, was stiffer and had a higher proportional limit than the agar duplicating compounds. These results would be expected, since the agar duplicating compounds are more dilute than the agar impression materials. Agar duplicating compounds A, D, and F were similar in their compressive properties, while compounds $\mathrm{C}$ and $\mathrm{E}$ had lower compressive characteristics. This again would be anticipated because of the lower agar concentrations used in materials C and E. Material B was a plastic gel duplicating material and had compressive properties similar to agar duplicating compounds at low compression values. This material had considerably higher strength and ultimate compression values than did the agar types. It is important to point out that these high values are 
not required of a duplicating material. It may, however, affect the length of time over which the duplicating compound may be used before the physical properties deteriorate to such an extent that the material must be discarded.

The ultimate per cent compression of the agar duplicating compounds was generally lower than for the impression compounds, but no correlation existed between these values and the other compressive properties.

The shape of the stress-strain curves was different from those reported by Paffenbarger. $^{2}$ The initial portion of the curves in Figure 2 were straight lines, but between a strain of 0.1 and $0.2 \mathrm{inch} / \mathrm{inch}$ the curves began to rise. After this rise they flattened out and finally became discontinuous when the specimens ruptured. This shape may

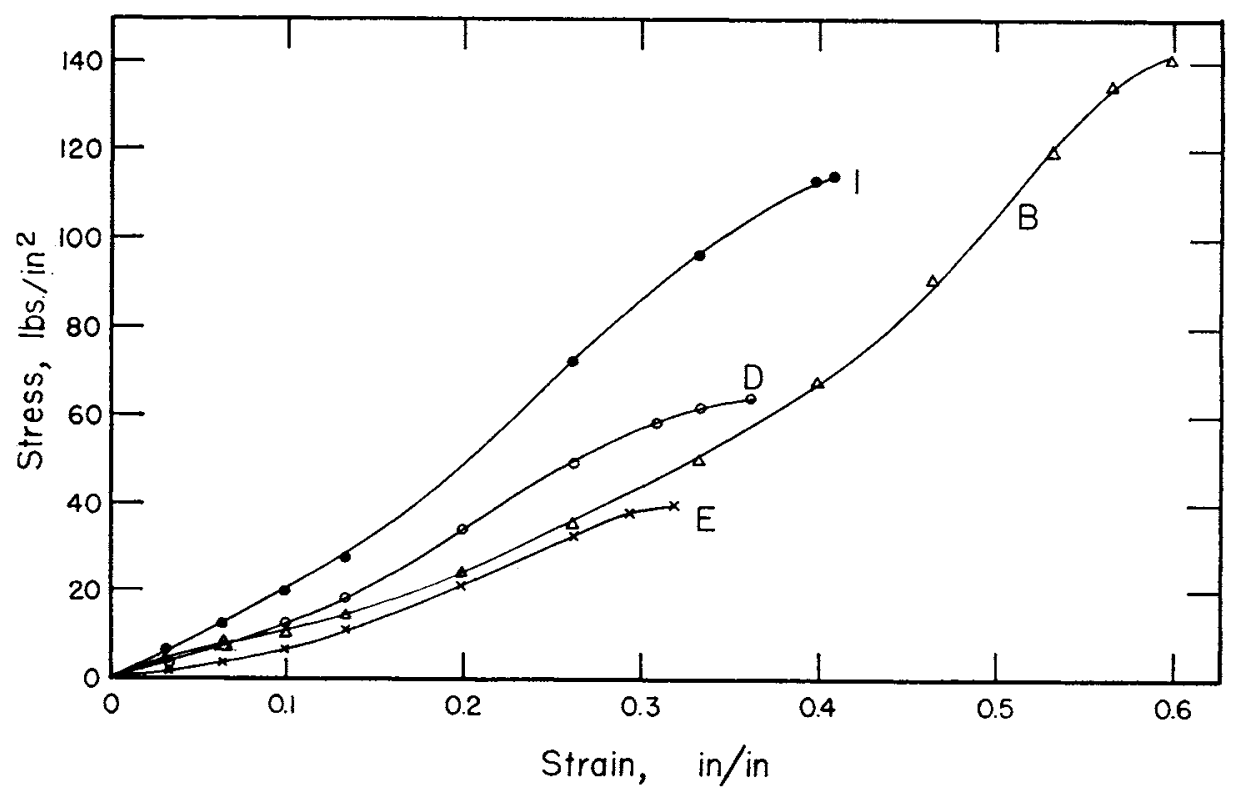

Fig. 2.-Stress-strain curves for duplicating compounds B, D, and E, and impression compound I

be explained by the fact that the specimen cross-sectional area is increasing during the test or that the stiffness of the material increases with the deformation. The stressstrain curves reported by Paffenbarger ${ }^{2}$ were usually concave toward the strain axis. The differences in the results of the two studies may be reconciled by noting that the latter stress-strain curves were obtained by loading the specimens at the rate of 2.84 $\mathrm{lb} / \mathrm{in}^{2} /$ minute, and therefore, the tests required 10-17 minutes to complete. Considerably more viscous deformation could occur in this period of time compared to the 3 seconds or less required in the present study. Any flow taking place would result in the stress-strain curve being concave toward the strain axis. The curves shown in Figure 2, therefore, more nearly represent the behavior of the agar materials in service, since the impression is removed rapidly rather than slowly.

Compressive strength.-The compressive strengths of the duplicating compounds are shown in Figure 3, those for the agar impression compounds in Figure 4, and those for the experimental agar gels in Table 3 . The compressive strengths, measured at a 


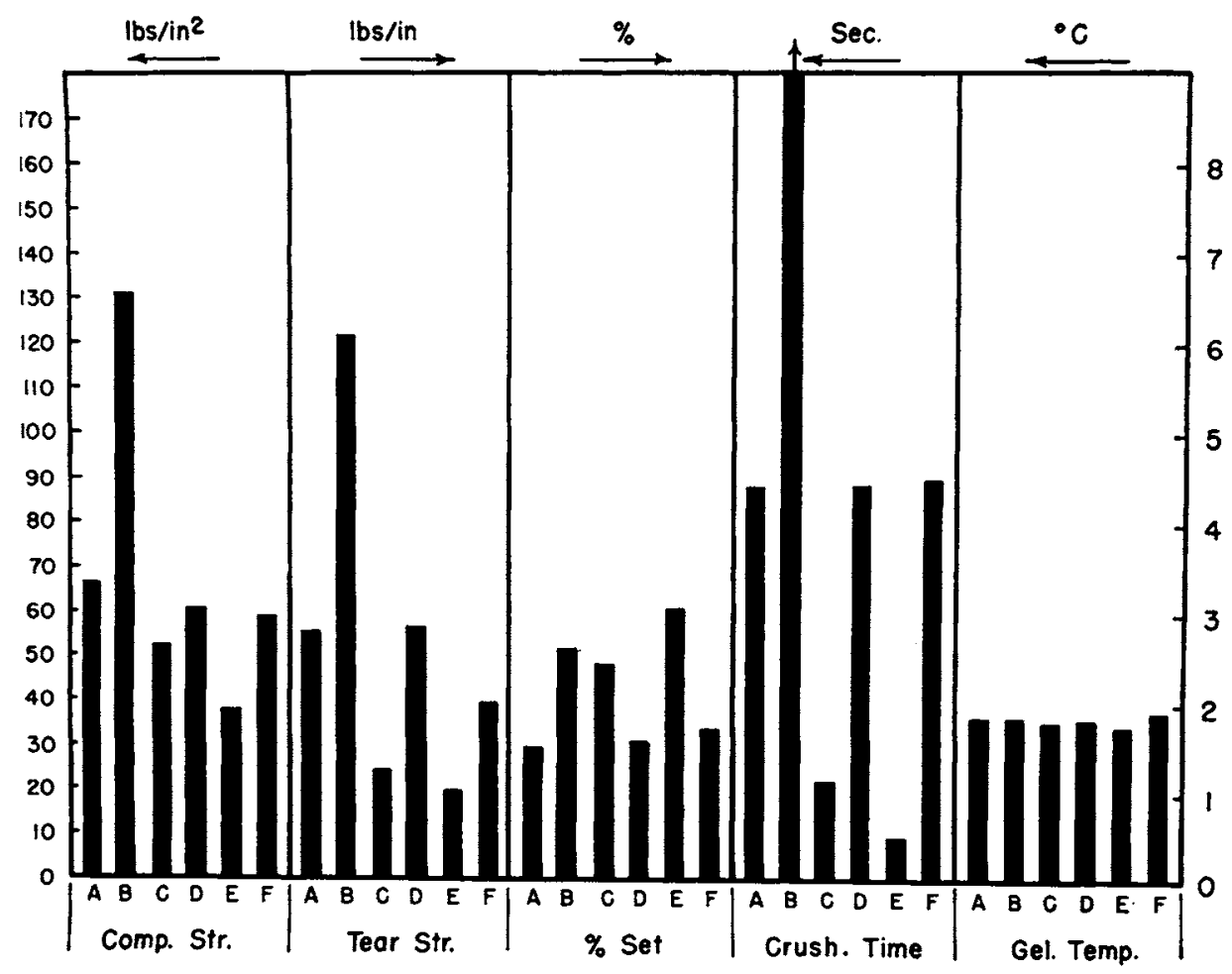

Fig. 3.-Properties of duplicating compounds

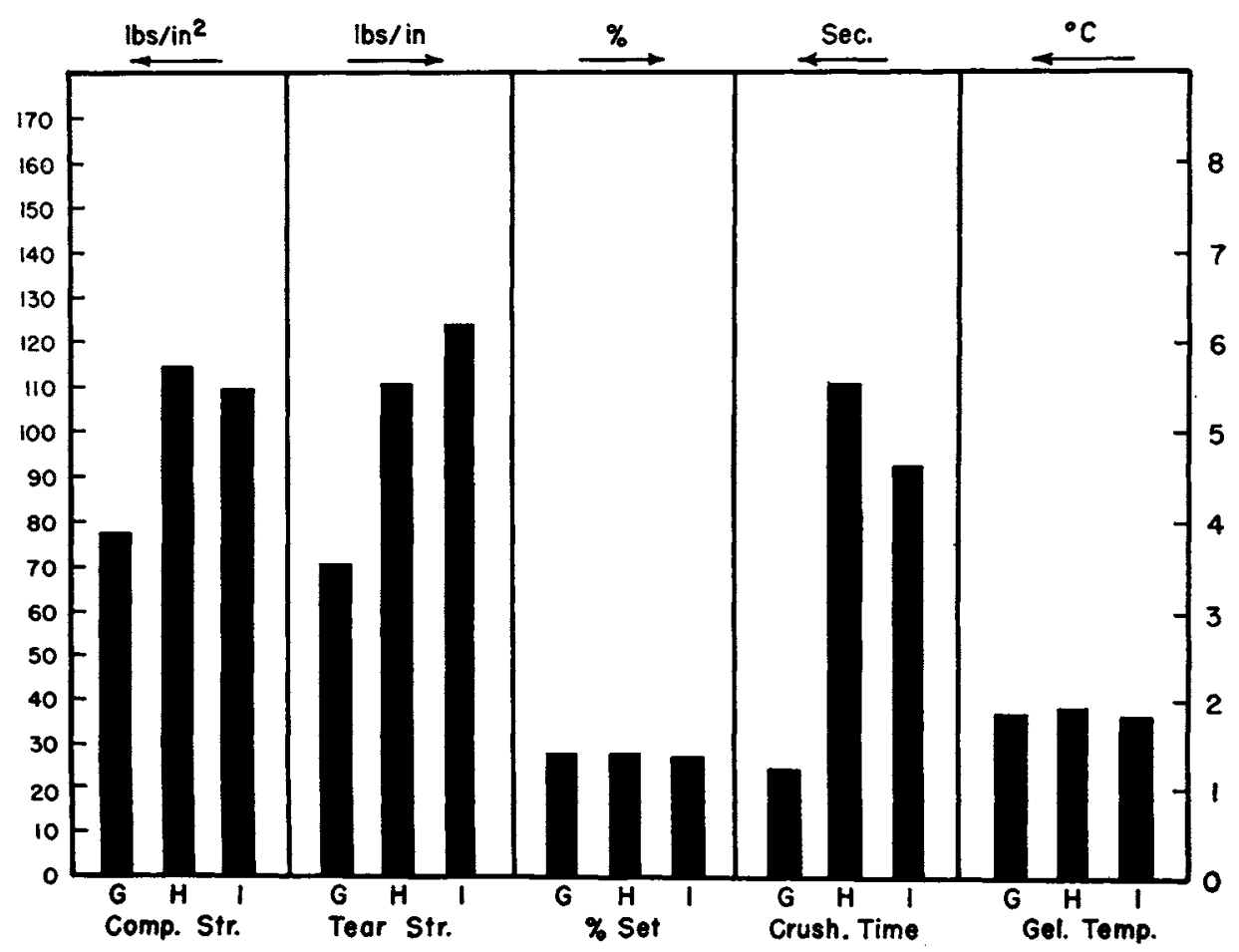

Fig. 4.-Properties of impression compounds 
deformation rate of 10 inches/minute, of the duplicating compounds generally ranged between 50 and $65 \mathrm{lb} /$ square inch. Two exceptions to this generalization were compounds $B$ and $E$. Compound $B$ is a plastic gel and would be expected to have the much higher compressive strength of $130 \mathrm{lb} /$ square inch, and agar compound $\mathrm{E}$ is diluted more than the other agar compounds and would be expected to have the lower strength of $37 \mathrm{lb} /$ square inch.

The compressive strength of the agar impression compounds $\mathrm{G}, \mathrm{H}$, and I fall between 78 and $114 \mathrm{lb} /$ square inch. These values are higher than for the duplicating compounds, since the agar concentration is two to three times higher than for the duplicating compounds.

The compressive strengths of experimental agar gels listed in Table 3 show considerable variation. The Portuguese, Spanish, and Japanese agar gels showed more variation between batches than did the American agar gels. The Spanish and Portuguese

TABLE 3

Physical Properties of 5 Per Cent Commercial Agar Gels

\begin{tabular}{|c|c|c|c|c|c|}
\hline Agar & Batch & $\begin{array}{l}\text { Compres- } \\
\text { sive } \\
\text { Strength } \\
\left(\text { lb } / \text { in }^{2}\right)\end{array}$ & $\begin{array}{c}\text { Crushing } \\
\text { Time } \\
\text { (Seconds at } \\
870 \mathrm{gm} / \mathrm{cm}^{2} \text { ) }\end{array}$ & $\begin{array}{c}\text { Per Cent } \\
\text { Set }\end{array}$ & $\begin{array}{c}\text { Gel } \\
\text { Tempera- } \\
\text { ture, } \\
\left({ }^{\circ} \mathrm{C} .\right)\end{array}$ \\
\hline American . & $\left\{\begin{array}{l}1 \\
2 \\
3 \\
4 \\
5\end{array}\right.$ & $\begin{array}{l}38 \\
38 \\
40 \\
32 \\
36\end{array}$ & $\begin{array}{l}26 \\
16 \\
19 \\
13 \\
13\end{array}$ & $\begin{array}{l}1.6 \\
2.4 \\
2.6 \\
2.5 \\
2.4\end{array}$ & $\begin{array}{l}36 \\
\cdots 37 \\
36 \\
36\end{array}$ \\
\hline Portuguese & $\left\{\begin{array}{l}1 \\
2\end{array}\right.$ & $\begin{array}{l}60 \\
52\end{array}$ & $\begin{array}{l}359 \\
134\end{array}$ & $\begin{array}{l}1.5 \\
1.6\end{array}$ & $\begin{array}{l}36 \\
36\end{array}$ \\
\hline Spanish. & $\left\{\begin{array}{l}1 \\
2\end{array}\right.$ & $\begin{array}{l}70 \\
53\end{array}$ & $\begin{array}{r}337 \\
53\end{array}$ & $\begin{array}{l}1.6 \\
2.3\end{array}$ & $\begin{array}{l}36 \\
36\end{array}$ \\
\hline Japanese. & $\left\{\begin{array}{l}1 \\
2\end{array}\right.$ & $\begin{array}{l}27 \\
16\end{array}$ & $\begin{array}{l}7 \\
1\end{array}$ & $\begin{array}{l}1.7 \\
3.9\end{array}$ & 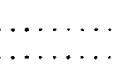 \\
\hline
\end{tabular}

agar gels were stronger than the Japanese and American, having compressive strengths from 52 to $70 \mathrm{lb}$ /square inch. The American agar gels were intermediate in compressive strength, with the values from 32 to $40 \mathrm{lb} /$ square inch, while the Japanese agar gels were the weakest, having values between 16 and $27 \mathrm{lb} /$ square inch. The experimental agar gels contained approximately the same concentration of agar as did duplicating compound $\mathrm{E}$.

Of principal interest is the stability of the properties of the American agar gels prepared from various batches of agar. The variability of the properties of agar from batch to batch has been recognized for a long time as being one of the main difficulties in the preparation of a consistent agar impression or duplicating compound. This fact is substantiated by the variation in the properties of the Portuguese, Spanish, and Japanese agar.

The reason for the choice of a deformation rate of 10 inches/minute may be seen by examination of Figure 5 . The solid curves represent the relationship of the compressive strength to the deformation rate for three different dilutions of duplicating 
compound A. The same types of curves have been obtained for the other agar duplicating and impression materials, although the maximum is not so pronounced in the case of the impression compounds. The dotted line indicates the per cent compression at fracture of the agar gels prepared by diluting material $\mathrm{A}$ with $0.5,1$, or 2 parts of water. All the values fell on a single curve, which showed that within this dilution range the percent compression was independent of the water to material ratio.

The curves for the compressive strength of agar gels versus deformation rate reached a maximum between 10 and 12 inches/minute. If the gels were deformed at low rates, such as 2 inches/minute, or at high rates, such as 20 inches/minute, considerably lower values for compressive strengths were obtained. A maximum was not observed for the per cent compression versus deformation rate, but the values increased between 2 and 10 inches/minute, after which a stable value was maintained. The deformation rate of 10 inches/minute was therefore selected because a maximum value was obtained at this rate and because the materials as used would be subjected to compression forces at approximately this rate.

The significance of selecting the proper deformation rate for evaluating compressive

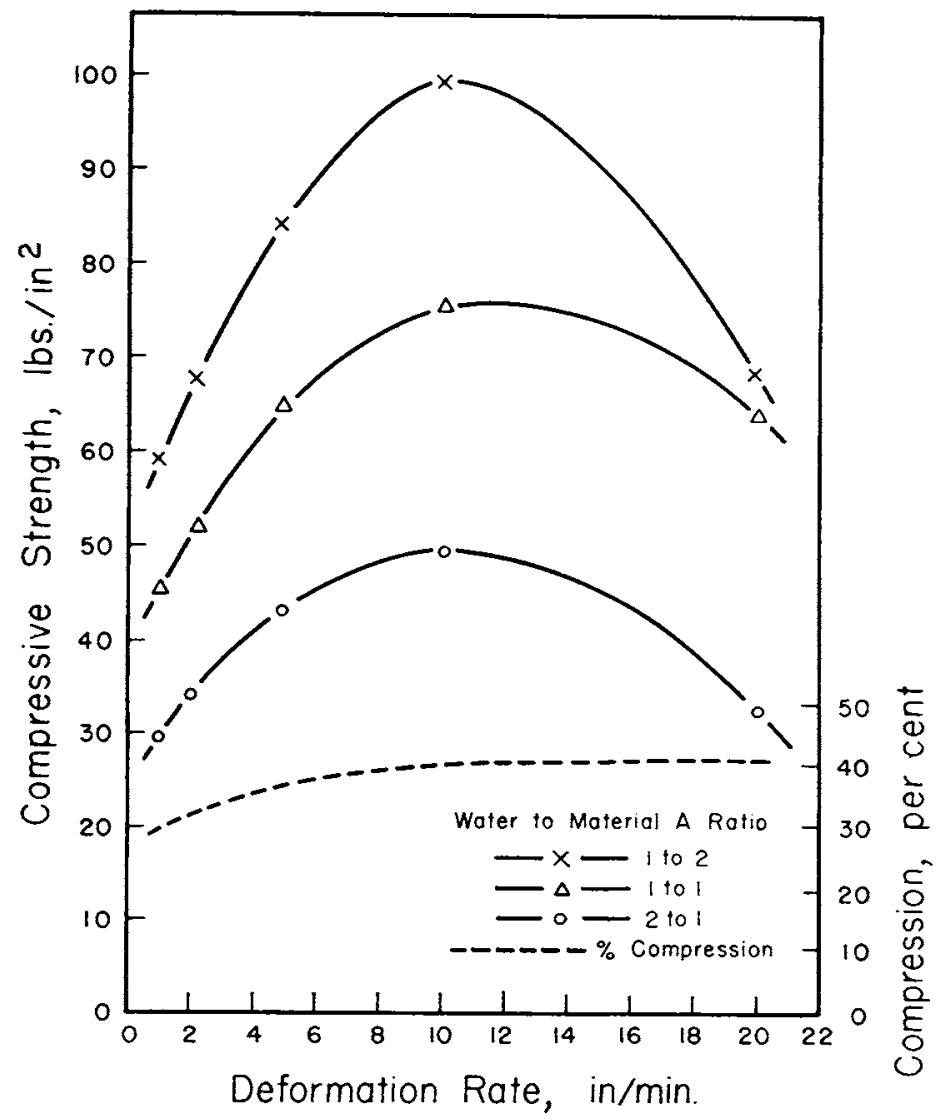

FIG. 5.-The effect of deformation rate on the compressive strength and per cent compression of duplicating material $\mathbf{A}$. 
strength may be seen by comparing the values reported by Paffenbarger ${ }^{2}$ for agar impression materials with those listed in Figure 4. The values given by Paffenbarger ${ }^{2}$ ranged from 16 to $40 \mathrm{lb} /$ square inch, while those reported in this study were between 78 and $114 \mathrm{lb} /$ square inch. The former values are possibly lower because the deformation rate was much slower.

Tear strength.- Since one visual criterion for discarding a duplicating material is the tendency of the material to tear in the region of the interproximal spaces, the tear strength of duplicating compounds is a most important property. The tear specimens were tested in tension at a rate of 10 inches/minute, and the values obtained for the duplicating and impression compounds are shown in Figures 3 and 4 .

The order of the tear strengths of the duplicating and impression compounds is essentially the same as for their compressive strengths. The tear-strength test, however, appears to be somewhat more sensitive to differences in materials than the compressive-strength test. The tear strengths of agar duplicating compounds $A, D$, and $F$ were between 2 and $3 \mathrm{lb} / \mathrm{inch}$, while compounds $\mathrm{C}$ and $\mathrm{E}$ had lower values of about $1 \mathrm{lb} /$ inch, and the plastic duplicating material had a higher value of over $6 \mathrm{lb} / \mathrm{inch}$. The tear strength of the agar impression compounds were approximately twice the value of the duplicating compounds, having values of 4-6 lb/inch.

In addition to the value of the tear strength, the rate at which a cast is removed from the duplication material is important. The effect of deformation rate on the tear strength of agar duplicating compounds $A$ and $D$ is presented in Figure 6. The results are similar to those obtained for the compressive strengths. The tear strength increased as the deformation rate increased from 1 to 10 inches/minute, after which the values appeared to decrease slightly, though not significantly. These results confirm the recommended procedure of snap removal of agar impressions.

Per cent set.-The per cent set after 12 per cent strain test was run by deforming the specimens 12 per cent for 1 minute, relieving the deformation, allowing a 1-minute rest period, and measuring the permanent deformation. The values for duplicating compounds, impression compounds, and experimental agar gels are listed in Figures 3 and 4 and in Table 3, respectively. The agar duplicating materials that had the higher compressive and tear strengths had per cent values of approximately 1.5. The weaker agar duplicating materials had per cent set values of 2.3-2.9. The plastic gel duplicating material gave a value of 2.6 per cent when evaluated according to this test procedure. There is some question whether this is a good test for materials of this type, since it recovers more slowly from a deformation than do the agar-type materials. A longer time of 5 minutes for recovery would be indicated when testing plastic gels. The stronger agar impression compounds had values of about 1.3 per cent, and little difference was observed between different products. All these values are less than 3 per cent, which is the limit suggested by the specification for agar impression materials. These data indicate that clinically these duplicating materials would function satisfactorily.

The per cent set values for the experimental agars listed in Table 3 were between 1.5 and 2.6, which is approximately the same range as that obtained for the commercial duplicating materials. One exception was the second batch of Japanese agar, which had a value of 3.9 per cent and, in general, appearal to be an inferior batch for dental purposes. 
The per cent set test does show large variations in agar gels but does not appear to be a particularly sensitive test. Large increases in the per cent set occur only when the material becomes excessively weak.

It should be pointed out that the per cent set will vary depending on the time allowed for the specimen to recover. The per cent set versus recovery time for duplicating compounds $\mathrm{A}, \mathrm{B}$, and $\mathrm{E}$ are shown in Figure 7. Material $\mathrm{E}$ is normally diluted 3 to 1 , but the per cent set versus recovery time curves were determined at 3 to 1 and 1 to 1 dilution, in order to show the effect of agar concentration.

The change in per cent set with recovery time was very slight with duplicating compounds $\mathrm{A}$ and $\mathrm{E}$, which were diluted 1 to 1 in their preparation. When material $\mathrm{E}$ was used at a 3 to 1 dilution, the per cent set was higher at all comparable recovery times, and the change with time was more pronounced. The change in per cent set with time for the plastic duplicating compound was most pronounced, decreasing from 3.2 per cent at $1 / 2$ minute to 1.3 per cent at 10 minutes. Since 10 minutes usually elapses between withdrawing the master cast and pouring the refactory cast, the lower value of 1.3 per cent more nearly reflects the behavior of this material in service.

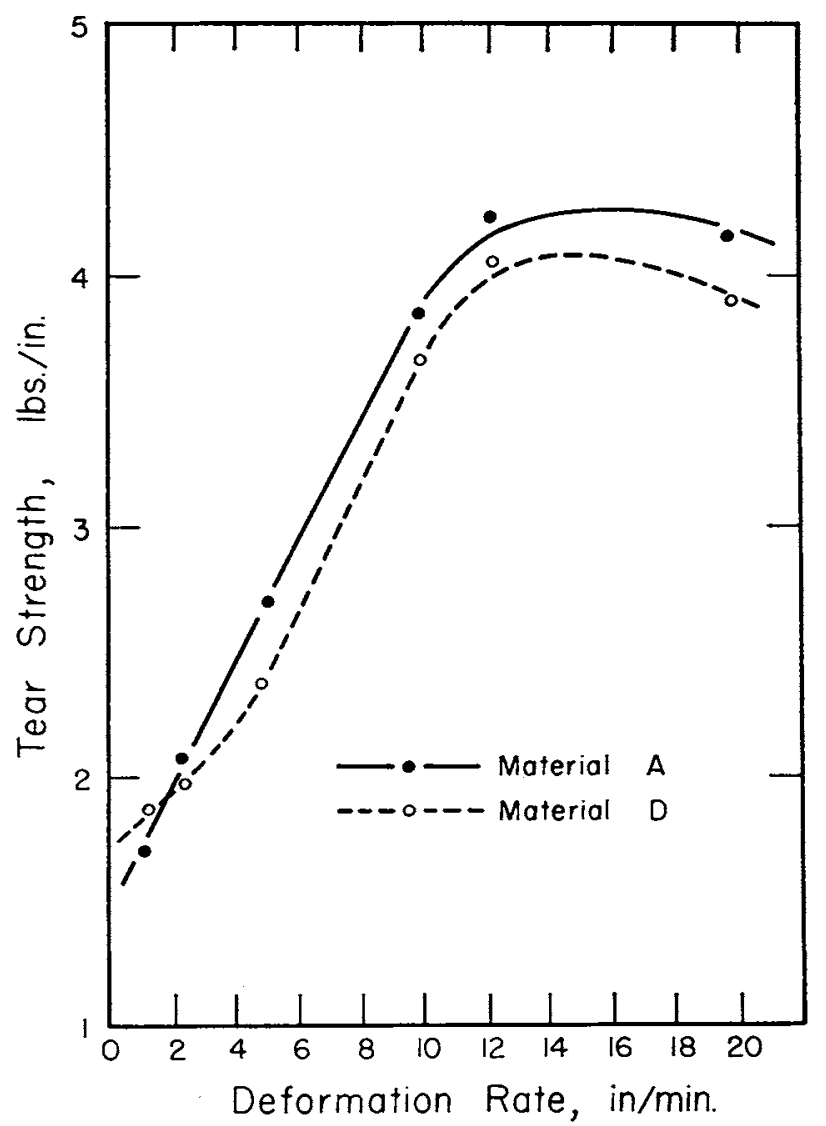

FIG. 6.-The effect of deformation rate on the tear strength of duplicating materials $A$ and $D$ 
These data illustrate that the per cent set test, although satisfactory for the evaluation of agar duplicating compounds, may give misleading results when used indiscriminately with other types of materials.

Crushing time.-The crushing-time tests on experimental agars, duplicating compounds, and impression compounds were determined using, 1,100-, 1,600-, and 3,600gm. loads, respectively. These loads correspond to stress values of $870,1,265$, and 2,845 $\mathrm{gm} / \mathrm{cm}^{2}$, or $12.4,18.0$, and $40.4 \mathrm{lb} / \mathrm{square}$ inch. These data are shown in Figures 3 and 4 and Table 3 . Unfortunately, it was not possible to use the same load to evaluate both duplicating and impression compounds. The relationship between the two scales is indicated by the fact that the impression compound $G$, having the lowest crushing time

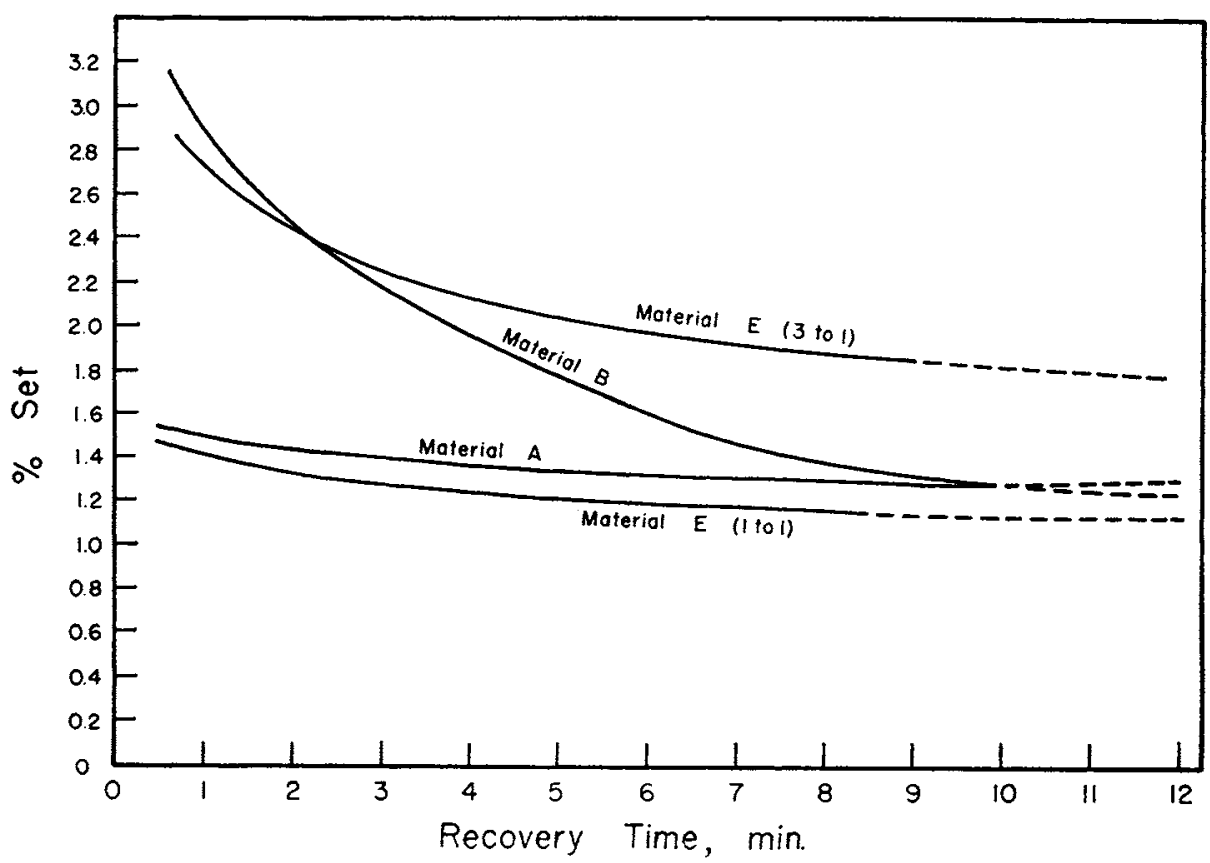

FIG. 7.-The per cent set of duplicating materials $A, B$, and $E$ with varying recovery times

of 25 seconds at a stress of $2,845 \mathrm{gm} / \mathrm{cm}^{2}$, had a crushing time of 360 seconds when tested at the stress of $1,265 \mathrm{gm} / \mathrm{cm}^{2}$ used on the duplicating compounds. Conversely, agar duplicating compounds $\mathrm{A}, \mathrm{D}$, and $\mathrm{F}$, which had crushing times of approximately 90 seconds at a stress of $1,265 \mathrm{gm} / \mathrm{cm}^{2}$, gave values of $1-2$ seconds at $2,845 \mathrm{gm} / \mathrm{cm}^{2}$ stress used to test impression compounds.

The crushing times of about 90 seconds for duplicating compounds $A, D$, and $F$, of 10-20 seconds for materials $\mathrm{C}$ and $\mathrm{E}$, and greater than 180 seconds for the plastic gel compound $\mathrm{B}$ are in the same general order as the compressive and tear strengths and in the inverse order of the per cent set values. The crushing time for the duplicating compound B was also determined at the stress of $2,845 \mathrm{gm} / \mathrm{cm}^{2}$ used in studying impression compounds, and a time of 50 seconds was obtained. This value was intermediate 
to the value of 25 seconds for impression compound G and 90-110 seconds for impression compounds $\mathrm{H}$ and $\mathrm{I}$.

The crushing time probably shows differences between materials more clearly than any of the other tests used. This is emphasized by the variation in the times reported in Table 3 for the 5 per cent experimental agar gels. The crushing times, measured at a stress of $870 \mathrm{gm} / \mathrm{cm}^{2}$, varied from 1 to 359 seconds for batch 2 of the Japanese agar and batch 1 of the Portuguese agar. These data illustrate the variation expected in commercial agars used in the preparation of dental duplicating and impression compounds. It is interesting to note the consistency between the values obtained for the batches of American agars.

The reason why the crushing-time test is so sensitive to changes in elastic duplicating and impression materials is not entirely clear. Unpublished results concerning the aging of duplicating materials confirm these findings, and this test appears to be the most sensitive to changes in materials caused by aging. Study of the elastic, viscoelastic, and permanent deformation properties of these materials has indicated that, with the times required to crush the specimens, the test is evaluating a combination of elastic and viscoelastic properties of these materials under a certain per cent deformation. The compressive strength and per cent set test do not evaluate this combination of qualities.

Gelation temperature.-Of all the properties of agar duplicating and impression materials, the property of gelation temperature was the most constant. The values reported in Figures 3 and 4 and Table 3 show that the gelation temperature varied between $35^{\circ}$ and $38^{\circ} \mathrm{C}$. according to the A.D.A. specification No. 11 for hydrocolloid impression material-agar type. The galtion temperature versus agar concentration curve must have a very small slope, since a change from a $1: 1$ to a $3: 1$ dilution decreases the gelation temperature approximately $1.5^{\circ} \mathrm{C}$.

Duplicating qualities.-Any of the duplicating materials tested had elastic properties sufficiently adequate that a rupture-free impression of the master metal model, described in the A.D.A. specification No. 11, section 4.4.3, could be made. The dimensions of stone casts prepared from the impressions were compared with the brass master model. No significant difference was observed in the accuracy of the various duplicating materials evaluated.

\section{SUMMARY AND CONCLUSIONS}

The stress-strain properties, compressive strengths, tear strengths, per cent sets after 12 per cent strain, crushing times, gelation temperatures, and duplicating qualities of six duplicating compounds were determined and compared with properties of three agar impression compounds.

The strength properties of the duplicating materials were lower than those of the impression materials as a result of the lower agar concentration.

The duplicating compounds could be divided into three groups with respect to physical properties. The reversible plastic gel had the highest strength properties, the agar duplicating compounds diluted 1-1 with water had intermediate properties, and the agar compounds diluted with 2 or 3 parts of water had the lowest strength properties. 
Although differences existed in the strength properties of the various materials, little difference was observed in their gelation temperature or the duplicating qualities, which indicates that a wide variety of materials may be used for duplication procedures.

The stress-strain curves for these materials differed from those previously published. This probably results from the fact that it is now possible to determine the entire stress-strain curve in less than 3 seconds by using improved equipment. The stressstrain properties, therefore, more closely reflect the properties of these materials as used, since rapid removal of the impression or cast is usual in impression or duplicating methods.

The compressive and tear strengths of agar impression or duplicating materials were shown to be a function of deformation rate, the values reaching a maximum value at 10 inches/minute. These data are further substantiation for the practice of a snap removal of impressions or casts.

The time required to rupture a material at a constant stress, or crushing time, was found to be the most sensitive test for evaluating differences in agar materials, probably because it measures both elastic and viscoelastic characteristics.

The per cent set test was found to be a rather insensitive test, but it was able to show large variations in agar material. It was observed that the use of this test with another type of material could give misleading information if the recovery characteristics of the material are not considered.

The two major areas of aging and duplication accuracy, which are important to the evaluation of duplicating compounds, were not discussed but are currently being investigated and will be reported at a later date.

The assistance of G. C. Berry, D. R. Hegg, and R. C. Stanley in the collection of experimental data is gratefully acknowledged.

\section{REFERENCES}

1. SkInner, E. W., and KERN, W. R. Colloidal Impression Materials, J.A.D.A., 25:578, 1938.

2. Paffenbarger, G. C. Hydrocolloidal Impression Materials: Physical Properties and a Specification, J.A.D.A., $27: 373,1940$.

3. Luster, E. A. Dimensional Changes of Agar-Agar Gel on Immersion in Various Sulphate Solutions, J. D. Res., 30:281, 1951.

4. Primlips, R. W., and Ito, B. Y. Factors Influencing the Accuracy of Reversible Hydrocolloid Impressions, J.A.D.A., $43: 1,1951$. Swartz, M. L., Norman, R. D., Gillmore, H. W., and PhininPS, R. W. Studies on Syneresis and Imbibition in Reversible Hydrocolloid, J. D. Res., 36:472, 1957.

5. Margetis, P. M., and Hansev, W. C. Changes in Agar-Agar Type Duplicating Material and AgarAgar on Heating and Storage, J.A.D.A., 54:737, 1957.

6. Paffendarger, G. C., Stanford, J. W., and Sweeney, W. T. American Dental Association Specifications for Dental Materials, pp. 42-46. 3d ed. Chicago: A.D.A., 1958.

7. A.S.T.M. Standards 1958, Part 9, Tear Resistance of Vulcanized Rubber, D624-54, pp. 1357-60. Philadelphia, Pa.: American Society for Testing Materials, 1958.

8. CResson, J. Suggested Revisions for Testing Dental Elastic Impression Materials, J. D. Res., $28: 573,1949$. 